\title{
ALGUMAS IMPLICAÇÕES TECTÔNICAS NA GÊNESE DAS MINERALIZAÇÕES SULFETADAS DO TIPO PANELAS NO VALE DO RIBEIRA, SP E PR*
}

\author{
ALEDIR P. BARBOUR**, BENJAMIN BLEY DE BRITO NEVES** \\ E RODI ÁVILA MEDEIROS***
}

\begin{abstract}
SOME TECTONIC IMPLICATIONS IN THE GENESIS OF MASSIVE BASE METAL SULFIDES TYPE "PANELAS" IN VALE DO RIBEIRA, SÃO PAULO AND PARANA STATES, SOUTHERN BRAZIL. Fumas, Lageado, Bairro da Serra, Panelas, Barrinha, Paqueiro, and Rocha district sulfide mineralization hosted in carbonate rocks of Precambrian Açungui Group in Vale do Ribeira region constitute a stratigraphkal level with common genetic characteristics, - denominated "Panelas" level. Rhitmic, repetitive marine transgressions and regressions characterized through alternative carbonate and terrigenous sediments associated to turbiditic complexes and debris flows, characterise a continental tectonic platform environment with mobile areas, convenient for exhalative geothermal sedimentary processes Vertical movements fixed the boundaries of shallow euxinic basins, responsible for base metal mineralizations in the region.
\end{abstract}

Keywords: Base metal sulfides, Panelas, tectonic implications, Vale do Ribeira, São Paulo, Paraná.

\begin{abstract}
RESUMO As mineralizações sulfetadas de Furnas, Lageado, Bairro da Serra, Panelas,Barrinha, Paqueiro e Rocha, encaixadas em rochas carbonáticas pré-cambrianas do Grupo Açungui no Vale do Ribeira, constituem um nível estratígrâfíco com características genéticas comuns, denominado nível Panelas. Trangressães e regressões marinhas rítmicas, configuradas por meio da alternância de sedimentos carbonáticos e terrígenos associados à complexos turbidíticos e fluxo de detritos, definem um ambiente tectônico de plataforma continental com setores móveis próprios para processos geotermais sedimentares exalativos. Movimentos verticais delimitaram bacias euxínicas rasas com condições favoráveis para a formação de mineralizações sulfetadas do tipo Panelas.

Palavras-chaves: Mineralizações sulfetadas, Panelas, implicações tectônicas, Vale do Ribeira, São Paulo, Paraná.
\end{abstract}

INTRODUÇÃO Histórico das Correlações Estratigráficas e das Jazidas Sulfetadas Desde 1922, o Vale do Ribeira tem produzido minérios de chumbo e prata. Esta região, estrategicamente localizada entre os Estados de São Paulo e Paraná (Fig. 1), tem sido objeto de vários projetos de pesquisa para a elucidação de problemas tanto geológicos, estratigráficos e estruturais, como também metalogenéticos. Pesquisas objetivando a concepção e elaboração de modelos genéticos para depósitos minerais são de importância vital para a elaboração de projetos de prospecção e pesquisa mineral. Entretanto, até a década de 1970, grande parte dos trabalhos publicados propunham uma origem hidrotermal para os depósitos do Vale do Ribeira, ligando-os direta ou indiretamente a soluções ascendentes provindas de focos magmátícos superficiais ou profundos. Até esta fase, as mineralizações conhecidas restringiam-se a um nível localizado na porção superior do Grupo Açungui, nível este denominado posteriormente "nível Panelas". Depois de 1970, foi definido um novo nível de sulfetos, encaixados em calcoxistos, localizado na chamada "Seqüência Perau", sotoposta ao Grupo Açungui. Este nível mineralizado, denominado desde então "nível Perau", fez-se acompanhar de um séquito de características que o colocaram em um contexto genético vulcanogênico. Metavulcânicas mais representativas, formações ferríferas bandadas (exalitos) e baritas associadas suscitaram sua correlação com o tipo "Kuroko". Trataremos neste trabalho, apenas do tipo Panelas.

Desde os primórdios da mineração e especialmente nas últimas duas décadas, a faixa calcária central do Vale do Ribeira, em sua porção SW (Fig. 2), tem se mostrado a região potencial mais promissora para mineralizações sulfetadas e fluorita. Muito embora prospectos e ocorrências tenham sido registrados no Vale do Ribeira, jazidas de metais base $(\mathrm{Pb}, \mathrm{Zn}$ e
$\mathrm{Cu}$ ) e fluorita parecem insistentemente restringir-se à faixa calcária central.

Desde o limite SW desse pequeno distrito, localizado em torno da Jazida do Rocha ( $\mathrm{Pb}, \mathrm{Zn}$ e Ag) e da jazida da Bayer (F), até o limite NE, balizado pela Jazida de Furnas ( $\mathrm{Pb}, \mathrm{Zn}$ e Ag) (Fig. 2), algumas correlações estratigráficas relacionando os níveis sulfetados já foram feitas. Merecem menção os trabalhos de Borges Suva et al. (1982), que correlacionaram as Jazidas de Apiaí/Furnas com aquelas do Rocha, dentro do distrito mencionado, estendendo para NE para fora e correlacionando também com a Jazida de Ribeirão Alegre, na região de Itapeva. Assim, também a equipe MMAJ/JICA (1982) correlacionou no mesmo nível estratigráfico as Jazidas do Rocha, Barrinha e Panelas. Em relatório posterior, correlacionaram também a este mesmo nível a Jazida do Paqueiro. A equipe faz ainda correlação destas jazidas com aquelas do Lageado e Bairro da Serra, localizando-as na mesma unidade estratigráfica. Segundo eles, apenas a Jazida de Furnas está localizada em uma unidade carbonática superior, separada da unidade carbonática por um filito denominado Ramal. Estas unidades estratigráficas serão tratadas em capítulo posterior.

Há várias razões para que essas correlações sejam novamente retomadas. As mineralizações sulfetadas, assim como as variáveis tectônicas diretamente relacionadas à gênese destas mineralizações, apresentam inúmeras similaridades que não devem ser o produto de mera coincidência. Serão discutidas oportunamente estas similaridades, bem como algumas discrepâncias, na apresentação dos resultados desta pesquisa.

GEOLOGIA GERAL Ambiência Geotectônica As considerações sobre a ambiência geotectônica do chama-

\footnotetext{
* Financiado pela FINÈP/PADCT, projeto n* 42.86.0545.00

** Instituto de Geociências, Universidade de São Pauto, Caixa Postal 20899, CEP 01498, São Paulo, Capital, Brasil

*** Petrobrás, Rua Ministro Correia Melo, 113/901, CEP 22430, Rio de Janeiro, RJ, Brasil
} 


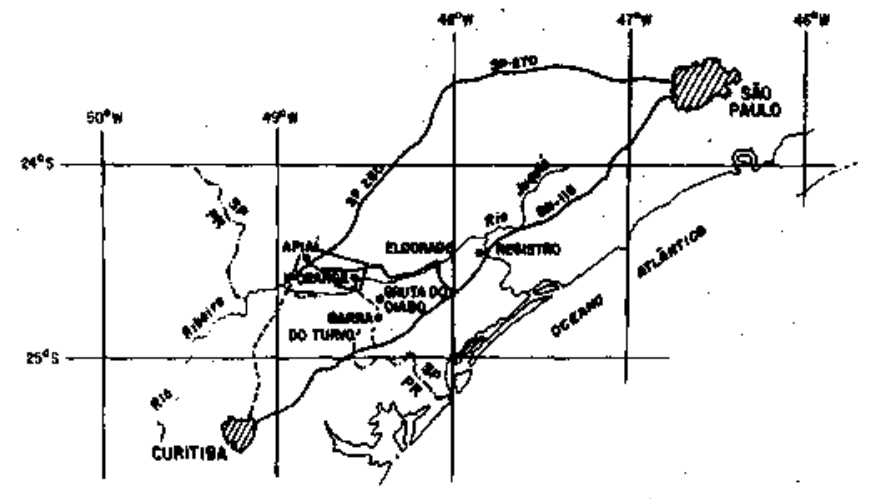

Figura I - Mapa de localizaçäo e acesso d area Figure 1 - Area locelibation and and map

do Sistema de Dobramentos Apiaí têm que ser colocadas de forma muito preliminar tendo em vista que muitos problemas de ordem geológica geral ainda estão em fase de equacionamento.

$\mathrm{O}$ distrito em pesquisa está situado entre dois acidentes geotectônicos maiores - o "Maciço de Catas Altas" (a deste) e o "Lineamento Lancinha", a leste, cujos significados geotectônicos são objeto de interpretações bastante variadas e controversas. O maciço granítico-migmático de Catas Altas é uma unidade geotectônica importante, podendo retratar um mobile core de um arco magmátíco proterozóico, que separou a faixa em apreço do sistema de dobramentos de Itaiacoca, a noroeste, com o qual guarda diversas similaridades geológicas gerais, inclusive paleoambientais. O "Lineamento Lancinha" apresenta um sistema transcorrente importante, possivelmente ligado às fases finais da tectogênese colisional do conjunto de escoamento da compressão. Nestes termos, a área em discussão constitui um típico "terreno" na linguagem mobilista, cuja composição e relações originais precisam ser estabelecidas ainda. Este "terreno" ou esta faixa apresenta uma série de características geológicas e faciológicas que permitem preliminarmente caracterizá-lo como fração de uma margem continental, do tipo Atlântico, no Proterozóico Médio-Superior (pré - $800 \mathrm{Ma}$ ), do tipo M5 (Kingston et al. 1983). Esta classificação (Kingston et al. 1983) leva em conta fatores como a composição da crosta subjacente ao contexto litoestrutural, o tipo de movimento tectônico causador da formação da bacia (possivelmente embasamento siálico) e a tectônica posterior de formação.

Essa "bacia/faixa" foi preenchida por uma sucessão de estádios marinhos transgressivos-regressivos, com predomínio de depósitos de águas rasas, compreendendo uma típica associação "quartzito-carbonato-folhelho", do Proterozóico, na concepção moderna de Condie (1982), onde os eventos deposicionais sobrepujaram eventos vulcânicos e plutônicos (que são importantes na faixa de Itaiacoca). Até a reconstituição da tectônica formadora, as divergências de interpretação podem ser facilmente contornadas, posto que estes mesmos aspectos foram, de uma forma ou outra, reconhecidos e descritos por vários autores.

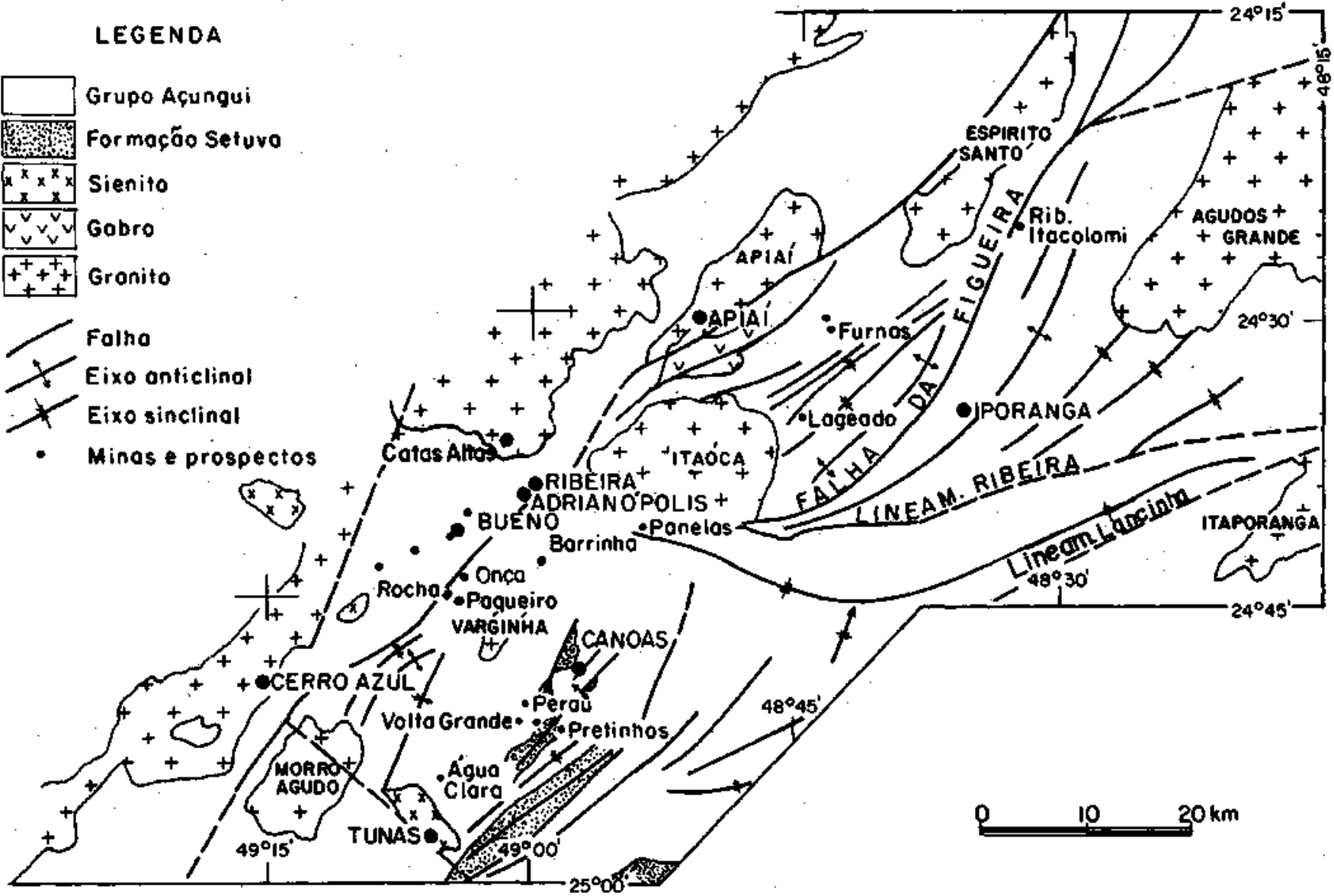

Figura 2 - Mapa de localização das minas e prospectos (JICA 1981, modificado) - Paqueiro inclui no mapa: Pessegueiro, Córrego do Eduardo e Diogo Lopes; Barrinha inclui no mapa: Cecrisa, Laranjal e Costão; Lageado inclui no mapa: Bairro da Serra Figure 2 - Mines and prospects map (JICA 1981, modified) - Paqueiro Mine comprises: Pessegueiro, Córrego do Eduardo and Diogo Lopes; Barrinha Mine comprises: Cecrisa, Laranjal and Costfio; Lageado Mine comprises: Bairro da Serra 
A bacia assim formada sofreu uma tectônica modificadora importante, provavelmente no final do Proterozóico ou Ciclo Brasiliano, resultando em um contexto de faixa de dobramento com variável grau de intensidade. Esses eventos deformacionais incluem certamente processos de colisão, no fechamento da margem continental, e processos associados de cisalhamento dentro e nas margens da faixa. A história deformacional (FB3B?, FB3F?), em suas linhas gerais e no detalhe, é foco de muitas dissensões entre os tectonistas, tanto em intensidade quanto em números de fases deformacionais.

Em termos de geologia regional, o terreno em pauta é parte do Sistema de Dobramentos Apiaí, situado a norte do maciço marginal de Curitiba, constituindo-se a porção central (ou Sistema Ribeira) da Província Estrutural da Mantiqueira, na concepção de Almeida et al. (1981).

CARACTERÍSTICAS GERAIS DAS JAZIDAS SULFETADAS DO TIPO PANELAS As denominadas jazidas sulfatadas do tipo Panelas exibem inúmeras características comuns, fundamentais na caracterização da tipologia e na correlação dos depósitos. Serão mencionadas a seguir as características comuns sobre as quais se baseia a correlação das jazidas e algumas peculiaridades superimpostas em processos de caráter geológico local.

- Em geral, os corpos são stratabound, limitando-se, mesmo em suas mineralizações epigenéticas, a rochas carbonáticas. Em caráter mais local, as mineralizações configuram corpos estratiformes.

- Lentes predominantemente concordantes com as encaixantes (Barrinha, Laranjal, Cecrisa e Costão).

- Lentes e veios concordantes e representativamente discordantes (Rocha, Paqueiro, Pessegueiro, Bueno, Córrego do Eduardo, Diogo Lopes, Panelas, Furnas e Lageado), definindo claramente corpos epigenéticos.

- Leitos carbonáticos enriquecidos singeneticamente em metais base com valores acima do background, a exemplo de Panelas.

- Áreas de fechamento dos veios concordantes e discordantes exibindo incremento de pinta seguido de calcita fina e grosseiramente cristalina. Exemplo na Jazida de Panelas e Furnas.

- Mineralização em zonas de brechação: Rocha.

- Alteração de paredes em veios que preenchem fraturas, exibindo silicificaçãb, comum, e sericitizaçâb e dolomitização, raras. Exemplos nas jazidas de Furnas, Rocha e Paqueiro.

- Mineralizações intensas nas proximidades e no contato, às vezes tectônico, de metacalcários capeados por filitos ou sericita xistos. Exemplos do Rocha, Lageado, Paqueiro, Bueno, Córrego do Eduardo, Diogo Lopes e Onça.

- Razão: $\mathrm{Ag} / \mathrm{Ag}+\mathrm{Pb}=0,050$

- Razão: $\mathrm{Zn} / \mathrm{Zn}+\mathrm{Pb}=0,053$.

Ressalta à primeira vista que os minerais mais comuns entre as jazidas são poucos, merecendo menção apenas pinta, galena e esfalerita. Estes, segundo as pesquisas realizadas e a bibliografia consultada, são quantitativamente representativos. Merecem menção ainda calcopirita, arsenopirita, tetraedritatennantita, estibinita, bornita, pirrotita, bornita, boulangerita, calcosina, argentita e prata nativa.

\section{MINERALIZACCÕES SULFETADAS DA REGIÃO DE FURNAS: SINGÊNESE VERSUS EPIGÊNESE AS} mineralizações sulfetadas mencionadas nesta área não foram ainda objeto de estudos mais recentes e aprofundados. Entretanto, elas são importantes, pois suas encaixantes carbonáticas preservam, mais do que todas as outras áreas mineralizadas do Vale do Ribeira, características primárias do ambiente de sedimentação. Por esta razão, elas merecem uma exposição de fatos e discussão com vistas às condições gerais de formação. $\mathrm{Na}$ forma como ocorrem hoje, os corpos mineralizados de Furnas são considerados, de maneira simplista, como produto exclusivo de epigênese. Ao se considerar que as mineralizações de Furnas, assim como as demais mencionadas dessa região, seriam formadas em um processo exalativo sedimentar, as relações das encaixantes com o nível mineralizado deveriam ressaltar predominantemente fenômenos de singênese. Uma vez que todos os pesquisadores da Jazida de Furnas enfatizam aspectos epigenéticos da mineralização, algumas considerações serão acrescentadas de maneira a esclarecer posições aparentemente tão opostas.

Sulfetos são precipitados como uma lama pesada, gelatinosa. Segue-se, então, um processo de litificação com a diagênese simultânea das encaixantes e dos sulfetos disseminados. Durante esse processo, as relações singênese e epigênese são alteradas. Estruturas sêdimentares de deslize pós-deposicionais (Songster \& Scott 1976), correntes de turbidez acrescentando material alóctone à capa das encaixantes do minério, e mesmo misturando-os ao horizonte mineralizado podem levar a uma obliteração das relações temporais de deposição das encaixantes e do nível mineralizado. Em adição, terrenos local e complexamente deformados deixarão de exibir registro das condições iniciais de deposição. Esta parece ser a situação da área de Furnas. Corpos mineralizados com contatos bruscos e transgressivos, concordantes e discordantes, zoneados ou homogêneos, interconectados, espessos e delgados, mas curtos, definem um quadro genético complexo, com sucessivas fases deformativas e rúpteis. Muitos dos aspectos mencionados parecem reportar-se às condições primárias iniciais de deposição e diagênese, agora quase que totalmente obliteradas.

Vejamos alguns fatos esclarecedores relacionados mais especificamente à jazida de Furnas:

- O horizonte carbonático mineralizado de Furnas localiza-se na Unidade Carbonática Inferior do Membro L-3 (MMAJ JICA 1984) ou Membro C2 da Formação Votuverava (Chiodi Filho 1984), unidade esta com atitude média local N 55E, 55 NW.

- Galena argentífera, esfalerita e pinta constituem a paragênese principal de Furnas, seguida por calcopirita, arsenopirita, estibinita e pirrotita. Oxidados contendo cerussita, anglesita, smithsonita, hidrozincita e limonita formaram-se ao longo de fraturas, cobrindo uma zona de mineralização projetada na superfície de extensão superior a $700 \mathrm{~m}$, e atingindo profundidades ao redor de $250 \mathrm{~m}$.

- Os corpos mineralizados mais representativos em dimensão alinham-se grosseiramente com um sistema de fraturas considerado quase paralelo à atitude dos litótipos encaixantes locais, N65-60E, mergulhando 45-55 NW. Esses veios são denominados concordantes. Eles se apresentam predominantemente zonados, com pinta fina estratificada, aparentemente in situ (Fig. 3). Segue-se de fora para dentro blenda e pirita fina fragmentada, evidenciando um certo deslocamento. A região central dos veios, especialmente aqueles mais espessos, está ocupada por galena predominante e esfalerita. A galena é grossa, evidenciando total remobilização e recristalização. A zona central do veio mostra evidências claras de deslocamento graças ao comportamento dúctil da galena. Os contatos do veio com os metacalcários são bruscos e muitas vezes parecem denotar um certo tectonismo. Localmente, a galena penetra pequenas fraturas definindo contatos transgressivos. Consideramos estes veios em seu conjunto como sin-díagenéticos submetidos a transladação em sua zona central.

Outro grupo de veios, menos representativo em dimensão, preenche um sistema de fraturas segundo a atitude N65-80 ${ }^{\circ}$, mergulho de 50 a $70^{\circ} \mathrm{SE}$. Esses veios são denominados discordantes; seus contatos são bruscos, o zoneamento mineralógico está ausente ou indiviso e não exibem pirita fina no contato com os metacalcários; são mais curtos e de menor continuidade lateral. Galena com alguma esfalerita remobilizada dos veios concordantes é translocada para fraturas discordantes, a pequenas distâncias, formando este grupo de veios. A galena e a esfalerita são alóctones e parecem deslocar-se 
apenas pela remobilização dúctil no estado sólido. A ausência de alteração das encaixantes é fato notório. Os processos deformatívos mencionados devem estar ligados à diagênese inicial e, principalmente, às condições tectônicas locais associadas ao metamorfismo regional. Consideramos tais veios como epi-cata-metagenéticos.

Um terceiro sistema de fraturas, menos representativo, alinhado segundo N80 a 90W, verticalizado, pode eventualmente conter mineralizações.

Algumas características gerais e peculiares desta jazida devem ainda ser acrescentadas:

- Veios curtos e relativamente espessos que dão uma relação comprimento/espessura própria para depósitos que indicam deformação extensiva.

- Intersecção de dois sistemas de fraturas mineralizados, configurando prismas mineralizados, exibindo espessamentos, adelgaçamentos e inflexões de contato, impostas por fases tectônicas sin e pós-mineralização.

- Mineralizações desenvolvidas em zona de transição entre metacalcários subjacentes e metadolomitos, contidas no horizonte carbonátíco, definindo uma jazida stratabound, ou com controle estratigráfico.

- Níveis delgados e estéreis de pirita em fraturas e que podem constituir guias para novos filões.

- Vugs revestidos de cristais de galena, implantados em camadas de galena maciça e pirita, e galena mais fina em fraturas cortando camadas mineralizadas mais antigas, denotando processos múltiplos de mineralização e/ou recristalização.

As encaixantes de Furnas não devem mais preservar traços geométricos texturais e químicos quantitativos e correlacionáveis aos corpos mineralizados por algumas das seguintes razões:

- Mineralização configurando, em vários de seus aspectos, origem distai em relação à fonte.

- Sucessivas transgressões e regressões marinhas intermeadas de complexos turbidíticos que caracterizam um ambiente de encaixantes alóctones em relação ao horizonte mineralizado.

- Remobilização intercamada extensiva nos veios concordantes e mesmo transladação nos veios discordantes, definindo uma interface de contraste físico-químico entre as encaixantes e os corpos mineralizados.

Em vista de todas estas características, consideramos a Jazida de Furnas, no sentido amplo, como uma jazida sin-sedimentar exalativa distai, submetida a remobilização intercamada extensiva e transladação de corpos para sítios estruturalmente controlados.

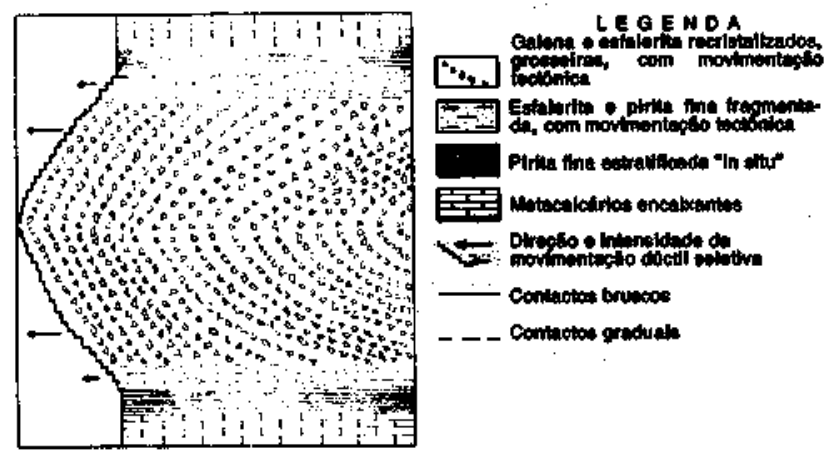

Figura 3 - Representação esquemática de veio sulfetado zoneado submetido a tectonismo - Mina de Furnas

Figure 3 - Schematic representation of a zoned sulphide vein submitted to tectonism - Fumas mine
RETROSPECTO BIBLIOGRÁFICO REFERENTE A ALGUNS ASPECTOS TECTÔNIÇOS DE MINERALIZAÇÕES SULFETADAS Em 1973, Asanalyev chamou a atenção para as mineralizações sulfetadas da região Central Tien Shan (Kazakhstão) ressaltando o caráter cíclico sedimentar das encaixantes pelito-carbonáticas de idade dévoniano-carboníferas da região mencionada. Cita ele que os depósitos acamados de $\mathrm{Pb} / \mathrm{Zn}$ desta região participaram de um processo rítmico e que estes sulfetos formaram-se no início de uma transgressão marinha, associados diretamente a carbonates, formando-se em zonas móveis de plataformas.

Mais recentemente, Russel (1983) destacou o fato de distritos com mineralizações representativas de $\mathrm{Pb} / \mathrm{Zn}$ revelarem uma relação direta com escudos submarinos ou sublacustrinos propensos à subsidência gradual. $\mathrm{O}$ mesmo autor mencionou Freeze (1966) que observou em Sullivan (Canadá), em escala regional, que as camadas que constituem a zona mineralizada "parecem ter sido depositadas durante a transição de um longo período de sedimentação em um ambiente de águas rasas para um período mais longo, de sedimentação em um ambiente de águas relativamente mais profundas, no qual deslizes submarinos e correntes de turbiditos são prevalecentes". Mencionou Russel (1983) que Jardine (1966) já descrevera o colapso do assoalho marinho abaixo do depósito de $\mathrm{Pb} / \mathrm{Zn}$ de Sullivan antes da precipitação do minério que permitiu a deposição, na depressão formada, de até $60 \mathrm{~m}$ de conglomerados derivados de rochas locais.

Russel concluiu, em trabalho publicado em 1978, que soluções hidrotermais começam o processo de exalação para dentro de um mar salino carbonífero nas jazidas de Silvermines na Irlanda, durante o crescimento dos Waulsortian bank, que se formam apenas quando o assoalho marinho está próximo do limite da zona fótica, talvez a uma profundidade de aproximadamente $200 \mathrm{~m}$ (Lees et al. 1977), Miller \& Grayson (1972). .Uma das características do minério e dos horizontes na capa é a ocorrência de fluxos de detritos que incluem clastos de galena sedimentar em uma matriz carbonática. $\mathrm{O}$ crescimento rápido desses "bancos", em algumas áreas da Irlanda e Inglaterra, até atingir espessuras de $500 \mathrm{~m}$, atestam sobre o caráter regional da subsidência. Aos bancos estão relacionadas também as jazidas de Navan, Tynagh, Lisvernane, Keel, Ballinack eHaberton.

Os depósitos Australianos de HYC (McArthur River) associam-se a carbonates na lapa e contêm estromatólitos e recifes algais, que dão lugar a cherts de águas profundas (depositados abaixo da zona fótica de acordo com Oehler \& Logan 1977), que são precursores da mineralização de $\mathrm{Pb} / \mathrm{Zn}$ em lamas anóxicas piritosas. Cita ainda Russel (1983) que a deposição do minério foi diluída na ocasião por brechas de deslize dolomíticas e turbiditos (Cotton 1965), eles mesmos indicativos do desenvolvimento de uma falha relacionada à depressão.

As condições de águas rasas das jazidas de Mount Isa (Austrália) são expressas por sedimentos da capa por meio de estromatólitos e camadas planas de conglomerados (Neudert \& Russel 1981). Russel (1983) reproduziu os dois autores anteriormente citados ao observar que as condições de águas rasas retornam após o episódio da mineralização de $\mathrm{Pb} / \mathrm{Zn}$.

O próprio Russel (1983) fez menção a vários depósitos, definindo os traços tectônicos associados à mineralização, e, entre eles, a associação de fluxos de detritos com os sulfetos de $\mathrm{Pb} / \mathrm{Zn}$ de Broken Hill (Austrália), segundo Stanton (1986); os sulfetos de $\mathrm{Pb} / \mathrm{Zn}$ de Dugald River (Austrália), depositados em uma bacia que continuou a subsidir após a mineralização (Witcher 1975); os espessos horizontes portadores de minérios de Navan (Irlanda), que testificam rápidas subsidências (Sevastopulo 1979), e parte do minério que foi envolvida em um deslize gravitacional submarino na jazida XY em Howard Pass (Canadá), segundo Morganthi (1981).

Todos estes deposites apontam para fenômenos tectônicos que são exteriorizados por repentinos afundamentos do 
assoalho, seguidos da deposição de sulfetos a partir de soluções que se acham relacionadas direta ou indiretamente aos próprios fenômenos tectônicos responsáveis pelo afundamento.

Russel (1983) observou que jazidas exalatívas sedimentares parecem ter relação direta com a subsidência extraordinariamente rápida de uma porção quente da crosta continental submarina. Dos traços tectônicos impressos em províncias metalogenétícas, a subsidência parece ser o menos acidental. Uma tectônica em regime de distensão com adelgaçamento da crosta explica comodamente os fenômenos de subsidência e eventuais mineralizações associadas.

Desde o ciclismo rítmico deposicional em bacias rasas/mais profundas, relacionado a transgressões e regressões marinhas sucessivas, passando por variações laterais contrastantes de espessura, com processos tectônicos responsáveis por fluxo de detritos e turbiditos, e finalizando com carbonates mineralizados a $\mathrm{Pb} / \mathrm{Zn}$, acham-se, em escalas variáveis, representados na região Furnas-Lageado. Várias pesquisas e relatórios internos foram desenvolvidos na região Furnas-Lageado e publicados nos últimos anos. Dentre eles foram consultados Campos Neto (1983), Petri \& Suguio (1969), Daitx (1980), MMJA/JICA (1981, 82, 83 e 84), IPT relatório 2235219 sobre a "Geologia das Folhas Iporanga e Gruta do Diabo" (1986) e Pires (1988). A Tabela 1 reproduz as denominações, litologia e ambiente de formação de cada uma das unidades da região Furnas-Lageado segundo cinco autores, pormenorizando as descrições de dois destes autores.
Os quatro distritos do Vale do Ribeira onde a mineralização sulfetada tipo Panelas assumiu proporções de reservas representativas são: região de Furnas (Lageado, Bairro da Serra), Panelas, B aninha e Rocha (Paqueiro). Esta seqüência segue um perfil caminhando de NE para SW no mapa da figura 2. Esses distritos guardam entre si muitas semelhanças no que diz respeito às suas mineralizações. As semelhanças, assim como algumas diferenças, foram listadas anteriormente ao ser caracterizado o nível mineralizado Panelas.

A correlação das colunas estratigráficas nos distritos de Furnas, Panelas, Barrinha e Rocha está representada na figura 4. Esta correlação irá suscitar várias observações gerais de caráter geológico ambiental, assim como das condições de gênese das mineralizações sulfetadas.

De maneira pouco usual, foram representados hiatos litoestratigráficos com o objetivo de visualizar melhor a correlação lateral e a variação das espessuras entre as unidades homólogas das quatro áreas representadas.

Os autores divergem nos valores das espessuras das unidades. A tabela 1 mostra essas discrepancies. Na confecção do gráfico, assumimos valores mais próximos daqueles indicados pelo MMAJ/JICA (1982). Os valores assumidos estão representados também na mesma escala vertical.

A repetitividade dos litótipos terrígeno e carbonátíco é ressaltada de imediato na observação da tabela 1. Este aspecto geológico merece considerações mais profundas e será tratado no capítulo seguinte.

Tabela 1 - Denominações, litologia e ambiente deformação das unidades da região Furnas-Lageado, na concepção comparada de diferentes autores

Table I - Denominations, lithology, and environment of formation of the stratigraphic units of Furnas-Lageado region, in the compared conception of different authors

\begin{tabular}{|c|c|c|c|c|}
\hline CAMPOS NETO 1983 & $\begin{array}{l}\pi C A \\
1983\end{array}$ & $\begin{array}{l}\text { DAITX } \\
\text { atd. } 1983\end{array}$ & $\begin{array}{c}\text { CAMPANHA } \\
\text { etal } 1986\end{array}$ & PIRES 1988 (Ficies dopoidiona) \\
\hline 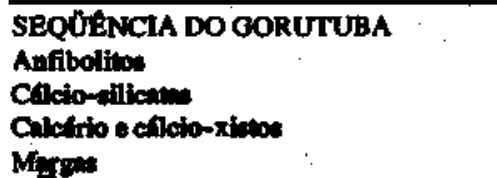 & $\begin{array}{l}\text { Membro } \\
\mathbf{S}_{4}\end{array}$ & $\begin{array}{l}\text { Unidede } \\
\text { Terigens, } s_{4}\end{array}$ & $\begin{array}{l}\text { Formegio } \\
\text { Gorutmbe }\end{array}$ & 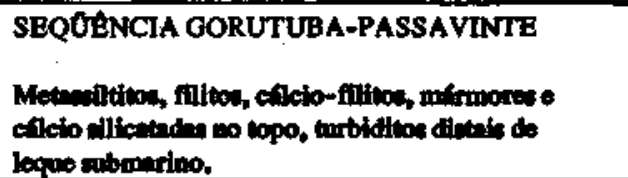 \\
\hline$( \pm 1400 \mathrm{~m})$ & $\begin{array}{l}\text { Membro } \\
L_{4}^{-650 m}\end{array}$ & $\begin{array}{l}\text { Uniderde Car- } \\
\text { bonftica } \mathrm{L}_{4}\end{array}$ & $\begin{array}{l}\text { Formegrio } \\
\text { Pana Vinte }\end{array}$ & 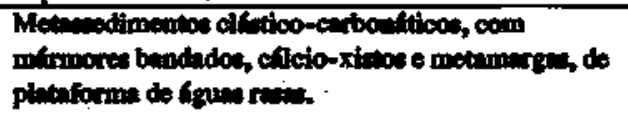 \\
\hline 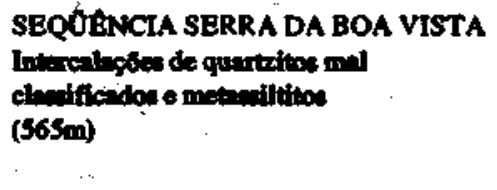 & $\begin{array}{l}\text { Mowbro } \\
\text { S3 }\end{array}$ & $\begin{array}{l}\text { Unidiede } \\
\text { Terrigena } \\
\text { S }\end{array}$ & $\begin{array}{l}\text { Formagio Sern } \\
\text { do Bon Virte - } \\
500 \mathrm{~m}\end{array}$ & 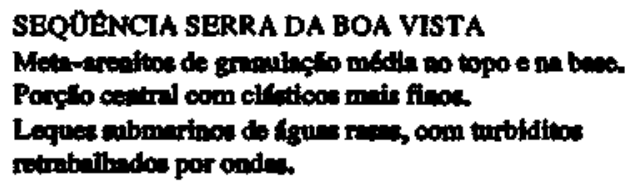 \\
\hline 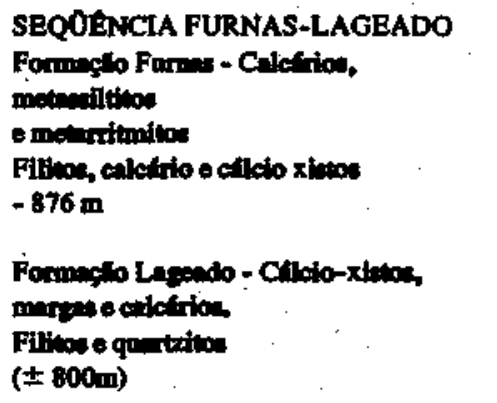 & $\begin{array}{l}\text { Membro } \\
\text { Lt-800m } \\
\text { Membro } \\
\text { S1-550m } \\
\text { Membro } \\
\text { L2-700m }\end{array}$ & 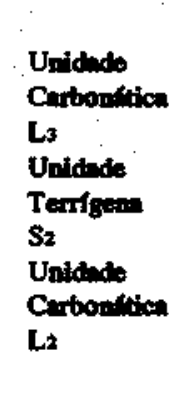 & 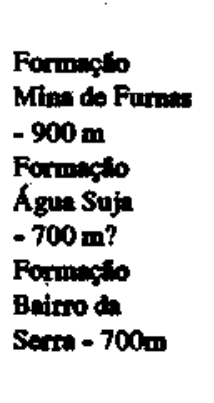 & 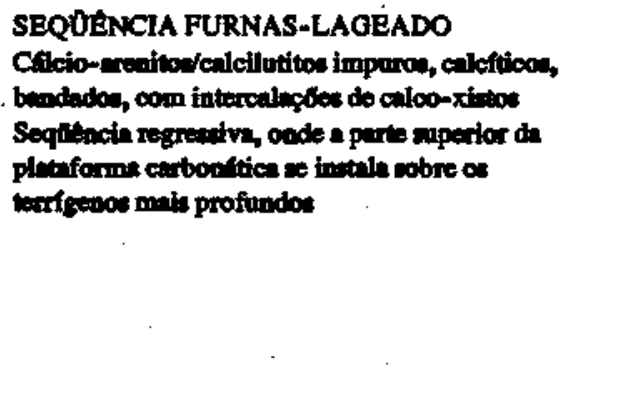 \\
\hline 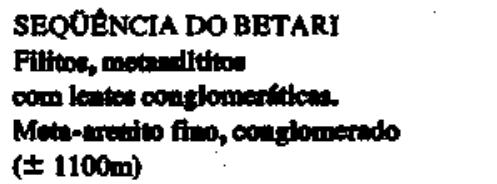 & $\begin{array}{l}\text { Momboo } \\
S_{1}\end{array}$ & $\begin{array}{l}\text { Undiado } \\
\text { Terfoton } \\
\mathbf{S}_{1}\end{array}$ & $\begin{array}{l}\text { Formulio } \\
\text { Beturl }\end{array}$ & 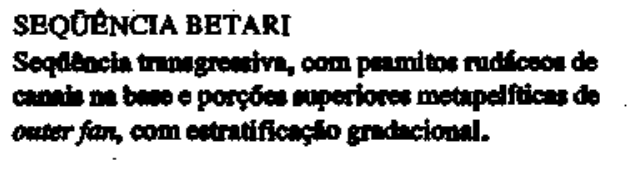 \\
\hline
\end{tabular}




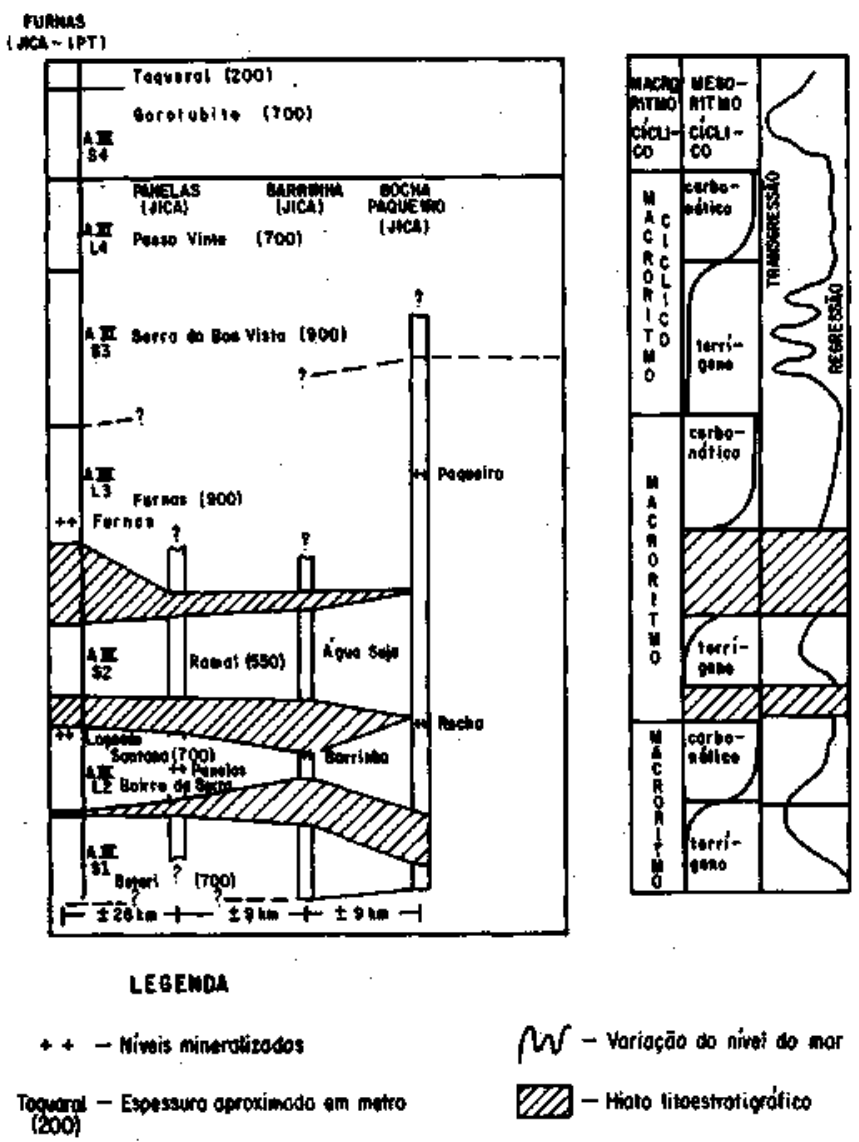

Figura 4 - Correlação estratigráfica entre as áreas Furnas, Panelas, Bamnha e Rocha-Paqueiro, sem empilhamento dos lüótípos ou inchando hiatos estratigráficos

Figure 4 - Statígraphic correlation between Furnas, Panelas, Bamnha and Rocha-Paqueiro, without piling up of lithotypes

CICLISMO TECTONO-SEDIMENTAR Além dos litótipos terrfgenos e carbonáticos se alternarem várias vezes dentro de cada um destes litótipos, observa-se outro ciclismo que, em períodos mais curtos ou mais longos, deve relacionarse a fatores cronotectònicos. Os ciclos, em seus períodos mais curtos ou longos, parecem interdependentes. A seção do lado direito da figura 4 foi construída com base na seção do lado esquerdo da mesma figura.

De acordo com a representatívidade na coluna estratigráfica das figuras 4 e 5, os ciclos foram classificados em três tipos, a partir dos menores: MICRORÍTMOS, que são acíclicos, irregulares (Fig. 5) e incluem lentes terrígenas nos carbonates e lentes de carbonates nos sedimentos terrígenos; não exibem continuidade lateral; MESORÍTMOS cíclicos separam as seqüências carbonáticas das terrígenas (Fig. 4), com continuidade lateral mínima de $\pm 44 \mathrm{~km}$, ao longo das quatro colunas representadas na figura 4; MACRORÍTMOS que fecham um ciclo e retornam às condições iniciais, com extensão lateral igual àquela dos mesorítmos.

A figura 6 representa um diagrama-tentativo contendo as seqüências deposicionais de níveis de mar baixo e conseqüentes sistemas de turbiditos, e seqüências deposicionais.de níveis de mar alto acompanhadas de possante sedimentação de onlap em camadas transgressivas. A ciclicidade está relacionada principalmente com as oscilações do nível do mar, suprimento e subsidência, favorecendo a formação de carbonates ou terrígenos.
Sobre o diagrama-tentativo da figura 6 , foi lançada a localização aproximada de algumas unidades litoestratigráficas da região Apiaí-Iporanga. Essas unidades contêm mineralizações. A ilustração ressalta de imediato que a mineralização está associada a um pacote de sedimentos que retrata um ambiente extremamente dinâmico e susceptível a atividades geotermais.

$\mathrm{Na}$ mesma figura, fica saliente o fato de as mineralizações sulfetadas mencionadas ocuparem uma posição no pacote de rochas carbonática/terrígenas, associando-se diretamente à plataforma carbonática e que ambas as fácies são co-participantes de um processo rítmico repetitivo de um ciclo sedimentar maior. Mesmo levando-se em conta que as mineralizações não mais se encontram no sítio original de deposição, depreende-se que no paroxismo da sedimentação carbonática do mesorítmo, em seu período de regressão marinha, as condições locais estagnantes (euxínicas) favoreceram a precipitação dos sulfetos de metais base.

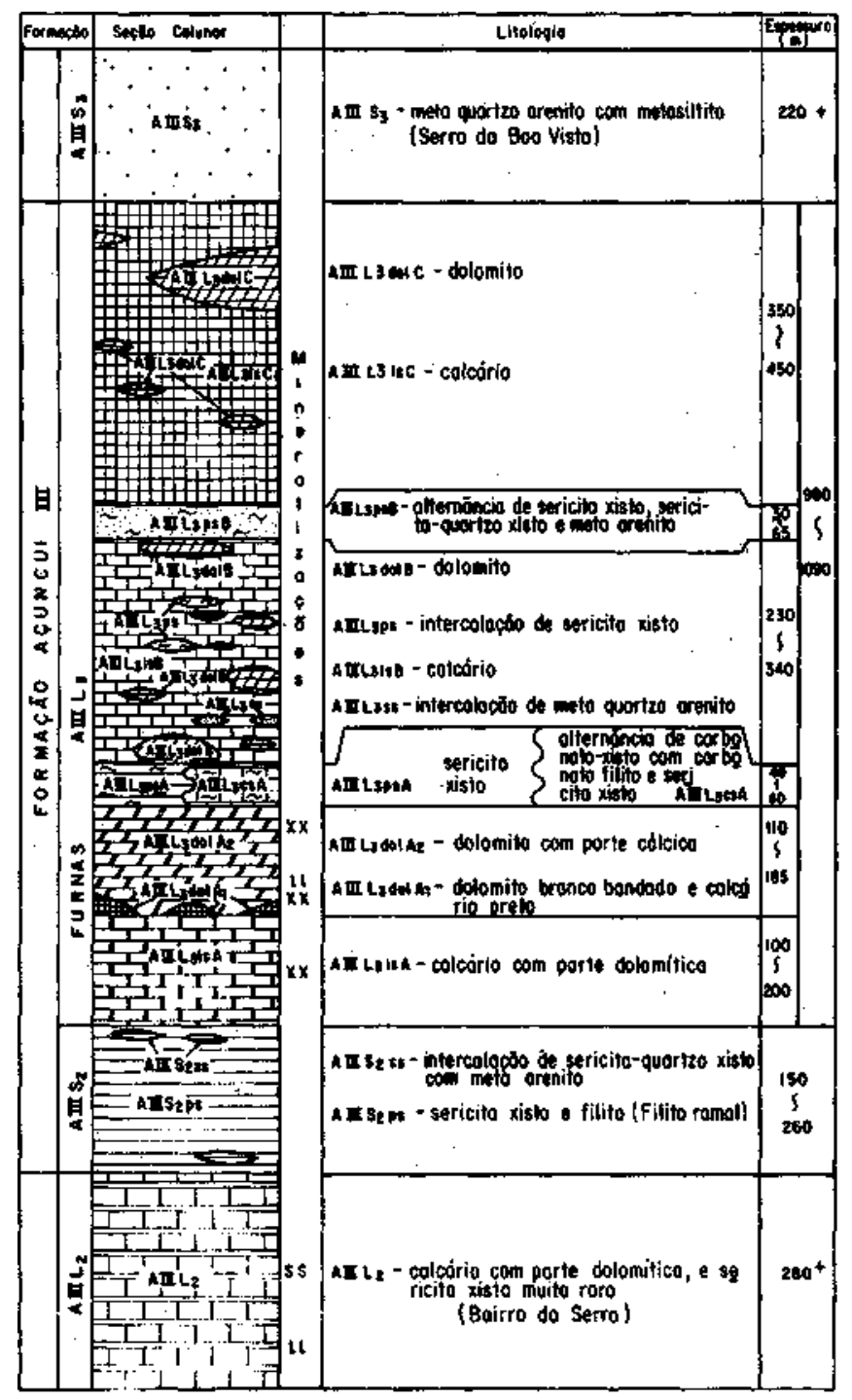

Figura 5 - Seção colunar estratigráfica da Área Fumas MMAJ 1983, Fig. II - 18, modificado. Mineralizações tipo Furnas (xx), Lageado, (11) e Bairro da Serra (ss) Figure 5 - Stratígraphic columnar section of Furnas Area MMAJ 1983, Fig. $\mathrm{n}-18$, modified. Mineralizations type Furnas (xx), Lageado (11), and Bairro da Serra (ss) 


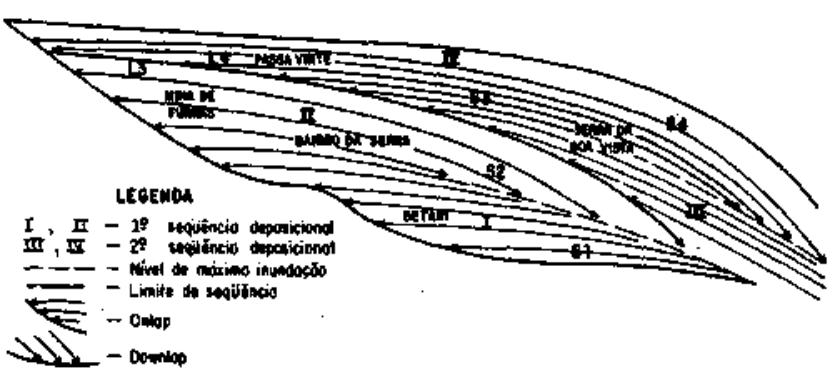

Figura 6-Diagrama - tentativo de seqüencias deposicionais para a seção Apiaí-Iporanga

Figure 6 - Tentative diagram of depoaciooal sequences for Apiaí-Iporanga region

A associação dos sulfetos com a camada carbonática portadora de matéria orgânica representativa, $\mathrm{Sr}$ alto e pinta disseminada, caracteriza a formação dos sulfetos em uma fácies paleogeográfica específica.

A mineralização limita-se a ambientes restritos de uma bacia de águas rasas, entre a zona costeira próxima da linha de praia e as partes de águas mais profundas de mar aberto, onde condições euxíhicas favorecem a precipitação e preservação de sulfetos estratiformes (Vaughan 1976). Ambiente redutor faz-se representar pelo acúmulo de uma lama rica em matéria orgânica. Estas condições são prevalescentes em baías, golfos ou partes marginais de bacias salinas em zonas pouco mais profundas; calcários, dolomites, barita e fluorita disseminada constituem uma paragênese própria desses locais.

Períodos cíclicos curtos e longos, ambiente de sedimentação raso e mais profundo, transgressões e regressões marinhas e complexos turbidíticos representativos são, em seu conjunto, resposta a setores móveis de uma plataforma continental sustentadora de sedimentos, sujeita a movimentos diferenciais de certa extensão e continuidade temporal.

A provável extensão do horizonte sulfetado a distâncias que hoje atingem meia centena de quilômetros expressa processos tectônicos e de mineralização de certa continuidade geográfica e temporal, em se considerando os $5.000 \mathrm{~m}$ de sedimentos cíclicos carbonático/terrígenos acumulados na região de Furnas, correspondentes à Seqüência Lageado.

Depósitos de $\mathrm{Pb}-\mathrm{Zn}$ exalativos encaixados em sedimentos formam-se em bacias epicontinentais que contêm seqüências sedimentares continuas e espessas e atingem alguns milhares de metros (Large 1981). Ao longo dessa bacia alguns sítios exibem movimentos tectônicos verticais mais acentuados, delimitados por blocos alçados. Os sítios são genética e morfologicamente favoráveis à ação de salmouras hidrotermais exaladas no assoalho marinho e ao longo das falhas que delimitam os blocos tectônicos. Nele formar-se-ia o nível mineralizado Panelas, ao longo de quase toda a sua extensão $(50 \mathrm{~km})$. Esta hipótese não implica em continuidade física da mineralização. Pequenas depressões com dimensões de algumas centenas de metros (Barrinha?), até alguns quilômetros (Rocha, Paqueiro?), constituiriam os sítios mais favoráveis para a deposição e preservação da mineralização sulfetada e estratiforme. O fato de não terem sido descritas mineralizações discordantes tipo stringer abaixo das mineralizações estratiformes constituiria um elemento básico para a caracterização dos depósitos conhecidos como distais, referindo-se ao centro de descarga, segundo o conceito de Large (1981).

$\mathrm{De}$ modo geral, depósitos de $\mathrm{Pb}$ e $\mathrm{Zn}$ pobres de $\mathrm{Cu}$ costumam formar-se em associações distantes Red Beds continentais e evaporitos (Gustafson \& Willians 1981). Entretanto, muitos dos depósitos sedimentares de $\mathrm{Cu}, \mathrm{Pb}$ e $\mathrm{Zn}$ formam-se em ambientes de sedimentação com sucessões de trangressões marinhas sobre red beds (Mufulira, África), alternando ambiente marinho com Red Beds terrestres (Mc Arthur River, Austrália e Tynah e Silvermines, Irlanda) ou sedimentos marinhos exclusivos (Rammelsberg e Meggen, Alemanha, e Sullivan, Canadá). Como útima observação, nas sucessões elásticas e químicas da região estudada não foram identificadas seqüências continentais tipo Red Beds ou evaporitos. Entretanto, esta possibilidade não é muito remota. A propósito, Daitx (1980) mencionou que a altíssima razão 1.000 $\mathrm{Sr} / \mathrm{Ca}$ (ao redor de oito) sugere que as rochas da seqüência Furnas talvez tenham se depositado em um ambiente hipersalino.

\section{ALGUMAS CONSIDERAÇÕES COMPLEMENTA-}

RES Ocorre na coluna estratigráfica da região SantanaFurnas uma unidade estratigráfica que recebeu diversas denominações das equipes que estudaram os locais onde ela acha-se representada. Foi denominada Membro 82 MMAJJICA (1983), Unidade Terrígena $\mathrm{S}_{3}$ (Daitx et al. 1983), Formação Água Suja (Hassui et al. 1984), Membro Tj (Chiodi Filho 1984) e Formação Água Suja (Campanha et al. 1986). A equipe MMJA-JICA (1983) correlacionou esta unidade em vários locais e a considerou presente na coluna estratigráfica dos distritos de Panelas, Barrinha e Rocha Paqueiro (Fig. 4). Ela separa os calcários Furnas dos calcários Bairros da Serra (Tab. le Fig. 7).

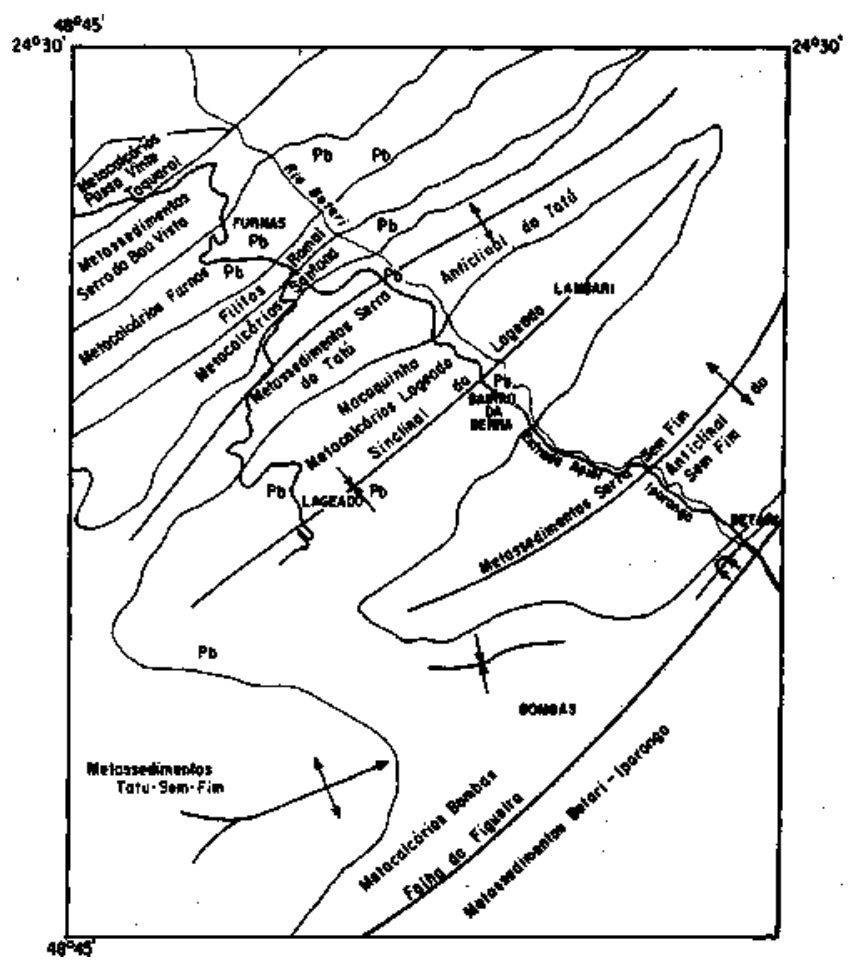

Figura 7 - Litologia e localização das mineralizações de chumbo nos metacalcários Lageado e Furnas (Melcher 1968, Cassedane 1972, Projeto SUDELPA 1975 e Daitx 1980, modificados)

Figure 7 - Lithology and localization of lead mineralizations in Lageado and Furnas metalimestones (Melcher 1968, Cassedane 1972, Project SUDELPA 1975 and Daitx 1980, modified)

A unidade está presente na coluna estratigráfica da área Furnas, que representa a aba NW do anticlinal (antiforma) da Serra do Tatu. Na aba SE deste mesmo anticlinal (antiforma), representada pelo Morro do Macaquinho e área do Bairro da Serra (Lageado), estes filitos não estão representados ou, 
talvez, sua espessura seja pequena demais para serem identificados e mapeados. A espessura desta unidade cresce de SE para NW, ou seja, do Bairro da Serra para Furnas (Fig. 4) e também de NE para SW, atingindo valores máximos no distrito Rocha-Paqueiro, com aproximadamente $1.000 \mathrm{~m}$. A espessura e continuidade geográfica da unidade configuram uma variação do nível do mar que não assume uma conotação episódica local, como pode parecer no distrito Bairro da SerraFurnas.

O estudo da distribuição de Ag e Zn nos minérios sulfetados do Vale do Ribeira exibiu também tendências expressivas nas direções SE-NW e NE-SW (Barbour et al. 1988). Estudos regionais de estratigrafia fundados na ambiência/tectonismo poderão futuramente lançar mais luz sobre a tendência de distribuição dos citados elementos, esclarecendo talvez o posicionamento original dos pacotes de rochas mineralizados antes da formação/transposição que ocorreram simultaneamente com a formação de um sistema de falhamentos expressos especialmente nas falhas de Lancinha e Morro Agudo, como movimentos essencialmente transcorrentes dextrógiros, com deslocamentos horizontais superiores a $100 \mathrm{~km}$ (Fiori 1985).

Listando e correlacionando todas as características das jazidas do nível sulfetado Panelas com os conceitos definidos na tabela 2 de Russel et al. (1981, pg. 117), que distingue depósitos exalativos sedímentares e vulcanogênicos, podemos posicionar as jazidas estudadas no primeiro grupo. As características das jazidas do nível Panelas aproximam-se bastante do modelo sedimentar. A profundidade de formação em ambiente marinho para as jazidas sedimentares varia de 50 a 200 $\mathrm{m}$, muito mais rasas do que as vulcanogênicas, que se situam em profundidades de $500 \mathrm{~m}$. As marcas de ondas observadas em alguns níveis da Seqüência Furnas definem uma profundidade não superior a $200 \mathrm{~m}$. Nos distritos mineralizados, o minério constituindo lentes empilhadas e encaixado em rochas carbonáticas com uma contribuição biogênica significante, salienta sua origem em um sistema exalativo sin-deposicional. Finalmente, a pequena representatividade e mesmo ausência de rochas vulcânicas contemporâneas aos pacote de rochas metassedimen tares da unidade Açungui, assim como a ausência de formações ferríferas bandadas, excluem processos vulcanogênicos diretamente relacionados às soluções exalativas mineralizantes.
CONCLUSÕES 1. As mineralizações sulfetadas encaixadas em rochas carbonatadas do nível Panelas apresentam, em grande parte do Vale do Ribeira, características comuns que permitem correlacioná-las em sua gênese.

2. Muitas das peculiaridades e diferenças entre as mineralizações decorrem de processos de litificação/diagênese/catagênese superimpostos a um processo genético primário comum. 3. Sedimentação em bacia marinha, com alternância de condições rasas a pouco profundas, cujo desenvolvimento deu-se em resposta à interação entre taxas de eustasia, subsidência e suprimento sedimentar. Estes fatores condicionaram oscilações do nível do mar, basculamento de fundo e ação de correntes de turbidez e fluxos de detritos, constituindo uma pilha sedimentar espessa. O domínio tectônico de plataforma carbonática com setores móveis sujeitos a movimentos diferenciais imprimiram as características principais das estruturas sedimentares, litótipos e as condições de mineralização.

4. As características somadas permitem definir as jazidas do tipo Panelas, em seus traços gerais, como um nível singenético com superimposição predominante de processos epigenéticos tectono/hidrotermais.

5. A distribuição de prospectos de sulfetos de metais base em uma vasta área geográfica, com extensão na direção NE-SW de mais de $150 \mathrm{~km}$, configura uma bacia de grande amplitude, com sítios isolados contendo concentrações econômicas de metais base.

6. As condições do ambiente de deposição associadas à tectônica ativa dominante apontam para processos extensivos de mineralização de $\mathrm{Pb}, \mathrm{Zn}, \mathrm{Cu}$ e $\mathrm{F}$ formados em um sistema geotermal exalativo sedimentar sindeposicional, comuns às várias jazidas do nível Panelas.

Agradecimentos Esta pesquisa tornou-se viável graças ao auxílio financeiro da FINEP/PADCT assim como à autorização de acesso aos dados geológicos e à Mina de Furnas. A gentileza do Diretor da Companhia Argentífera Furnas, sr. Francisco Henrique Neto e Engenheiro Called são extensivamente reconhecidas. A companhia do professor dr. Richard W. Hutchinson ressaltou alguns pontos críticos e polêmicos da Mina de Furnas. As revisões dos professores drs. João Batista Moreschi e Jorge Silva Bettencourt auxiliaram bastante na clareza do texto e de alguns conceitos geológicos.

\section{REFERÊNCIAS BIBLIOGRÁFICAS}

ALMEIDA, F.F.M.; HASSUI, Y.; BRITO NEVES, B.B.; FUCK, R.A. 1981. Brazilian structural province: an introduction. Earth $S c i$. Rev., 17(1-2):1-30.

ASANALYEV, H. 1973. Prospecting criteria for stratiform lead-zinc mineralization in sedimentary formations (as in Central Tien Shan)./nfer7i. GeoLRev., 15(12):1432-1439.

BARBOUR, A.P.; MACEDO, A.B.; HYPOLITO.R. 1988. Correlação dos elementos $\mathrm{Ag}, \mathrm{Pb}, \mathrm{Zn}, \mathrm{Cu}$ e $\mathrm{Fe}$ com $\mathrm{Ba}$ em algumas jazidas sulfetadas do Vale do Ribeira, Estados de SP e PR. Boi Inst. Geoc. 18:1-21. (USP, série científica).

CAMPOS NETO, M.C. 1983. Contribuição à litoestratigrafia do Grupo Acungui no sudeste do Estado de São Paulo. In: SIMP. REG. GEOL., 4, São Paulo, 1983, Atas... São Paulo, SBG. p. 103-112.

CAMPANHA, G.A. da C.; GIMENEZ FILHO, A.; CAETANO, S.L.V.; PIRES, F.A.; DANTAS, A.S.L.; TEIXEIRA, A.L.; DEHIRA, L.K. 1986. Geologia e estratigrafia da região das folhas Iporanga e Gruta do Diabo, Vale do Ribeira, São Paulo. In: CONOR. BRAS. GEOL., 34, Goiânia, 1980. Anais... Goiânia, SBG. v.2, p. 508-1073.

CASSEDANE, J. 1972. Estudo dos elementos traços e acessórios das galenas do Vale do Ribeira (SP). In: CONOR. BRAS. GEOL., 25, São Paulo, 1971. Anais... São Paulo, SBG. v.1, p. 11-119.

CHIODI FILHO, C. 1984. Contribuição à geologia das regiões sul paulista e leste paranaense - Grupos Açungui e Setuva. In: CONOR. BRAS. GEOL., 33, Rio de Janeiro. Anais... Rio de Janeiro, SBG. v.5, p.2394-2403.

CONDIE, K.C. 1982. Early middle proterozoic supracrustal sucessions and their tectonic setting. Am. J. Sci. 282:p.341-357.
COTTON, R.E. 1965. HYC lead-zinc-silver ore deposits. In: CONOR. EMPIRE MIN. METALL., 8, Melbourne, 1965. Proceeding... v.l, p. $197-200$.

DAITX, B.C. 1980. Prospecto de $\mathrm{Cu}$, Pb e Zn nas faixas carbonitícas Furnas-Lageado, São Paulo e Paraná. São Paulo, CPRM. 27p. (Rei. Int).

DAITX, E.C.; TAKAHASHI, A.P.; SILVA, C.R.; FERREIRA, J.C.G.; MAEYMA, O. 1983. Projeto Anta Gorda: mapeamento geológico da área norte, fase m. São Paulo, DNPM/CPRM. 1 v.

FIORI, A.P. 1985. As falhas Lancinha e de Morro Agudo e estruturas secundárias associadas. In: SIMP. SUL-BRAS. GEOL., 2, Florianópolis, 1985. Atas.... Florianópolis, SBG. v.1, p. 146-158.

FREEZE, A.C. 1966. On the origin of the Sullivan orebody kimberley. Brit. Col. Can. Min.Metatt., 8:263-294.

GUSTAFSON, L.B. \& WILLIAMS, N. 1981. Sediment-hosted stratiform deposits of Cooper, Lead, and Zinc. Econ. Geol. 75 th Anniv.v., p. 139-178.

HASUI, Y.; EBERT, H.D.; QUADE, H. 1984. Aspectos geológicos da megantiforma da Serra do Cadeado, PR. In: CONGR. BRAS. GEOL., 33, Rio de Janeiro, 1984. Anais... Rio de Janeiro, SBG. v.5, p.2380-2393.

JARDINE, D.E. 1966. An investigation of brecciation associated with the Sullivan mine orebody at kimberley $B$. $C$. Winnipeg, Manitoba. 185 p. (Thesis, Université de Manitoba).

KINGSTON, D.R.; DISHROON, C.P.; WILLIAMS, P.A. 1983. Global basin classification system. Am. Ass. Petr. Geol. Bull. 67(12):2175-2193.

LARGE, D.E. 1981. Sediment-hosted submarine exhalative lead-zinc 
deposits - a review of their geological characteristics and genesis. In: WOLF K. H. ed. Handbook of Stratabound and Stratiform ore Deposits. Amsterdam, Elsevier. 9:469-507.

LEES, A,; NOEL, B.; BOUW, P. 1977. The Waulsortian "reefs" of Belgian: a progress report. Mem. Inst. Geol. Univ. Louvam, 29:289-315.

MELCHER, G.C. 1968. Contribuição ao conhecimento do distrito mineral do Ribeira de Iguape, Estados de São Paulo e Paraná. São Paulo. 122p. (Tese de Livre Docência, Esc. Polit/USP).

METAL MINING AGENCY OF JAPAN. JAPAN INTERNATIONAL COOPERATION AGENCY. 1981. Report on Geological Survey of Anta Gorda. (Phasej.). Convênio DNPM/MM AJ/JICA.

METAL MINING AGENCY OF JAPAN, JAPAN INTERNATIONAL COOPERATION AGENCY. 1982. Report on Geological Survey of Anta Gorda. Convênio DNPM/MMAJ/JICA. (Phase 2).

METAL MINING AGENCY OF JAPAN. JAPAN INTERNATIONAL COOPERATION AGENCY. 1983. Report on Geological Survey of Anta Gorda. Convênio DNPM/MMAJ/JICA. (Phase 3).

METAL MINING AGENCY OF JAPAN. INTERNATIONAL COOPERACTION AGENCY. 1984. Report of geological Survey of Anta Gorda. Convênio DNPM/MMAJ/JICA. (Phase 4).

MILLER, J. \& GRAYSON, R.F. 1982. The regional context of Waulsotian Fades in Northern England. In: SYMPOSIUM ON THE PALEO-ENVIRONMENT SETTING AND DISTRIBUTION OF THE WAULSORTIN FACIES, El Paso, 1982. Proceeding... El Passo, Univ. Texas, p. 17-23.

MORGANTI, J.M. 1981. Ore deposit models 4 sedimentary type stratiform ore deposits: some models and a new classification. Geoc. Can. 8:65-75.

NEUDERT, M.K. \& RUSSEL, R.E. 1981. Shallow water and hypenaline features from the Middle Proterozoic Mount Isa Sequence. Nature, 293:284-286.

OELLER, J.H. \& LOGAN, R.G. 1977. Microfossils, cherts and associated mineralization in the Proterozoic Mcarthur (HYQ lead-zinc-silver deposit Econ. Geol., 72:1393-1409.

PETRI, S. \& SUGUIO, K. 1969. Sobre os metassedimentos do extremo sul do Estado de São Paulo. Convênio USP/DAEE. 98 p. (PublicaçSo especial).

PIRES, F.A. 1988. Urna nova concepção para os ambientes do Grupo Açungui, na região de Iporanga e Apiaí, sul do Estado de São Paulo. In: CONGR. BRÁS. GEOL., 35, Belém, 1988. Anais.. Belém, SBG.v.2,p.606-616.

PROJETO SUDELPA. 1985. Geologia. São Paulo, Sudelpa - CPRM. v.I4.
RUSSEL, M J. 1978. Douwnward-excavating hydrothermal cells and Irish-type ore deposits: importance of an underlyng thick Caledonian prism. Trans. Inst. Min. Met., 87(B):168-171.

RUSSEL, MJ.; SOLOMON, M.; WALSHE, J.L. 1981. The genesis of sediment-hosted, exhalative zinc-lead deposits. Mineralium Deposita, 16:113-127.

RUSSEL MJ \& SMITHE, DK 1983 Origin of the Oslo Graben in relation to the Hercynian - Alleghenian orogeny and lithospheric rifting in the North Atlantic. Tectonophysics, 94:457-472.

RUSSEL, MJ. 1983. Major sediment-hosted exhalative zinc+lead deposits; formation from hydrothermal convection cells that deepen during crustal extension. In: SANGSTER, D.F., ed. Sediment-hosted stratiform lead-one. Min. Assoc. Can., Short Course Handb. v.8, p.251-283

SANGSTER, D.F. \& SCOTT, S.D. 1976. Precambrian Stratabound massive $\mathrm{Cu}-\mathrm{Zn}-\mathrm{Pb}$ sulfide ores of North America. In: WOLF, K.H., ed. Handbook of Stratabound ore deposits. Amsterdam, Elsevier. 6:129-222

SILVA, R. B. da; MAEYAMA, O.; PEROSA, P.T.Y; ALMEIDA, E.B.; SARAGIOTTO, J.A.R. 1982. Considerações sobre as mineralizações de chumbo, zinco e prata do Grupo Açungui no Estado de São Paulo. In: CONGR. BRÁS. GEOL., 32, Salvador, 1982. Anais... Salvador, SBG. v.3, p.972-986.

SEVASTOPULO, G.D. 1979. the strati graphical setting of Basemetal deposits in Ireland. In: Prospecting in Areas of Glaciated Terrain. London, Inst Min. p. 8-15.

STANTON, R.L. 1976". Petrochemical studies of the environment at Broken Hill, New South Wales: 4-environmental synthesis. Trans. Inst. Min. Met., 85(8)221-233.

VAUGHAN, D J. 1976. Sedimentary geochemistry and the mineralogy of the sulfides of lead, zinc, cooper, and iron and their occurrence in sedimentary ore deposits. In: WOLF, K.H., ed. Handbook of Stratabound and Stratiform Ore Deposits. Amsterdam, Elsevier. 2:317-363.

WHTTCHER, I.G. 1975. Dugald River zinc-lead deposit. la KNIGHT, C.L., ed. Economic Geology of Australia and Papua New Guinea. I. Metals. Australas, Melbourne, Inst. Min. Metall. 5:372-376.

MANUSCRITO A649

Recebido em 14 de março de 1990 Revisão do autor em 17 de abril de 1990 Revisão aceita em 19 de abril de 1990 